\title{
Pengaruh Pelapisan Silane Coupling Agent Pada Papan Partikel Kenaf Dan Tandan Kosong Kelapa Sawit
}

\author{
Delovita Ginting ${ }^{1}$, Andrius ${ }^{2}$, Shabri Putra Wirman ${ }^{3}$, Yogie Muharman Lubis ${ }^{4}$ \\ 1,2,3, Dosen Program Studi Fisika, Fakultas Matematika dan Kesehatan, Universitas \\ Muhammadiyah Riau, Pekanbaru, Indonesia \\ 4, Mahasiswa Program Studi Fisika, Fakultas Matematika dan Kesehatan, Universitas Muhammadiyah Riau, \\ Pekanbaru, Indonesia \\ Delovita@umri.ac.id
}

\begin{abstract}
This study reports the effect of coating Silane Coupling Agent (SCA) on composite surfaces. Composites made from composite particulate kenaf fiber and empty oil palm bunches passing 50 mesh sieves using epoxy resin. The particle board compacting process was carried out using a Hydrolic Press compacting machine with a pressure of 20 Bars, holding time 10 minutes in the initial stages, and continued using a Hot Press compacting machine with a pressure of 20 Bars, temperature $150^{\circ} \mathrm{C}$, holding time 15 minutes. The process of treating the Silane Coupling Agent solution on the composite surface is done manually layered on the composite surface. Composites tensile strength were tested referring to ASTM D 638-14, impact strenght tested referring ASTM D 256-04, and Water Absorption using ASTM D 570. Surface examination was made with a Scanning Electron Microscope (SEM). The Silane Coupling Agent (SCA) coating has succeeded in increasing the bond between kenaf fibers, empty oil palm bunches and epoxy be effective and in accordance with increasing tensile strength, impact strength and water absorption.
\end{abstract}

Key words: Composite, Wood, Kenaf, Silane Coupling Agent, Empty Oil Palm Bunch

\section{Abstrak}

Penelitian ini melihat pengaruh pelapisan Silane Coupling Agent (SCA) pada permukaan komposit. Komposit partikel serat kenaf dan tandan kosong kelapa sawit seragam lolos ayakan 50 mesh dengan menggunakan resin epoksi. Proses kompaksi papan partikel menggunakan mesin kompaksi Hydrolic Press dengan tekanan 20 Bar dan waktu penahanan 10 menit pada tahap awal, dan dilanjutkan dengan menggunakan mesin kompaksi Hot Press dengan tekanan 20 Bar, suhu $150{ }^{\circ} \mathrm{C}$ dan waktu penahanan 15 menit. Proses treatment larutan Silane Coupling Agent pada permukaan komposit dilakukan secara manual berlapis pada permukaan komposit. Komposit diuji keteguhan tarik (tensile strength) mengacu ASTM D 638-14, kuat pukul (impact strenght) mengacu pada ASTM D 256-04 dan uji daya serap air mengacu pada ASTM D 570. Pengujian permukaan komposit dilakukan dengan Scanning Electron Microscope (SEM). Pelapisan Silane Coupling Agent (SCA) telah berhasil meningkatkan ikatan antara serat kenaf, tandan kosong sawit dan epoksi sehingga secara efektif dan sejalan dengan peningkatan kuat tarik, kuat pukul dan daya serap air.

Kata kunci : Komposit, Kayu, Kenaf, Silane Kopling Agen, Tandan Kelapa Sawit Kosong 


\section{Pendahuluan}

Pembuatan komposit merupakan salah satu alternatif dalam pemenuhan kebutuhan kayu karena material komposit mampu menggabungkan beberapa sifat material yang berbeda karakteristiknya menjadi sifat yang baru dan sesuai dengan desain yang direncanakan. Penggunaan komposit papan partikel dengan pemanfaatan serat yang berasal dari alam di berbagai bidang tidak terlepas dari sifat unggul yang dimiliki komposit serat yaitu ringan, kuat, kaku dan tahan terhadap korosi. Keuntungan mendasar yang dimiliki oleh serat yang berasal dari alam adalah jumlah berlimpah agar dapat diperbaharui dan didaur ulang serta tidak mencemari lingkungan (Fiore, 2015).

Salah satu serat alam yang banyak dimanfaatkan adalah serat kenaf komposit dalam dunia industri. Penelitian serat kenaf seperti yang dilakukan oleh Datta pada tahun 2015 meneliti pengaruh modifikasi serat kenaf pada morfologi dan sifat mekanik. Kenaf dapat dimanfaatkan sebagai serat alam menjadi material industri seperti produk furniture dan lain sebagainya.

Serat alam lain yang dapat dimanfaatkan dan dapat digabung menjadi komposit salah satunya adalah serat tandan kosong kelapa sawit. Data Pusat Statistik pada tahun 2017 bahwa perkebunan kelapa sawit secara nasional memiliki areal seluas 14.030 .573 juta hektar dengan jumlah produksi 37.812 .628 ton. Kegiatan pengolahan kelapa sawit menghasilkan limbah, salah satunya adalah limbah tandan kosong kelapa sawit yang jumlahnya $30 \mathrm{~s} / \mathrm{d} 35 \%$ dari total berat tandan buah segar yang diproses. Limbah ini cukup berlimpah sepanjang tahun namun penggunaannya belum maksimal, apalagi sebagai material industri dari serat.

Kelemahan serat alam adalah jeleknya kualitas ikatan yang terbentuk antara serat dan matrik, salah satu usaha untuk memperbaiki kualitas ikatan antara serat dan resin digunakan silane. Silane merupakan material perantara yang digunakan untuk membuat ikatan antara dua material khusus, maka silane disebut sebagai material coupling agent.

Berdasarkan potensi diatas penelitian ini berfokus pada studi pengaruh penambahan silane coupling agent terhadap sifat fisis dan mekanik komposit menggunakan limbah serat tandan kosong kelapa sawit dan serat kenaf dengan mengunakan resin epoksi.

\section{Metode Penelitian}

A. Proses Pembuatan Komposit

Komposit dibuat menggunakan serat kenaf dan tandan kosong kelapa sawit seragam lolos ayakan 50 mesh dengan menggunakan resin epoksi. Komposit dibuat dengan fraksi massa serat dan resin adalah 30\%:70\%. Proses kompaksi papan partikel menggunakan mesin kompaksi Hydrolic Press dengan metode tekan dingin (Cold Press) dengan tekanan 20 Bar dan waktu penahanan 10 menit pada tahap awal, dan dilanjutkan dengan metode tekan panas (Hot Press) dengan tekanan 20 Bar, suhu $150^{\circ} \mathrm{C}$ dan waktu penahanan 15 menit.

\section{B. Pelapisan Permukaan Komposit}

Silane dilarutkan ke dalam larutan yang terdiri dari etanol dan aquades, fraksi massa silane adalah $20 \%$, etanol adalah $72 \%$ dan aquades adalah $8 \%$ dari total massa (. Komposit yang sudah dilapisi dengan larutan silane 
dikeringkan dalam oven selama 2 jam dengan suhu $80^{\circ} \mathrm{C}$, kemudian didiamkan selama 24 jam untuk proses pengkondisian (Liu, Yinan, 2019). Proses pelapisan larutan Silane Coupling Agent pada permukaan komposit dilakukan secara manual berlapis pada permukaan komposit. Jumlah larutan silane yang digunakan adalah sebanyak $1 \%$ dari massa komposit.

\section{Pengujian Komposit}

Pengujian komposit dilakukan untuk melihat pengaruh pelapisan silane coupling agent (SCA) terhadap kekuatan tarik, kekuatan pukul, dan daya serap air. Kuat tarik komposit diuji menggunakan Universal Testing Machine Galdabini Gallarate mengacu pada ASTM D 638-14. Kuat pukul komposit diuji menggunakan Universal Testing Machine HT-8041A mengacu pada ASTM D 256-04. Daya serap air komposit diuji mengacu pada ASTM D 570. Pengujian permukaan komposit setelah pengujian kuat tarik dilakukan dengan Scanning Electron Microscope (SEM).

\section{Hasil dan Pembahasan}

A. Kuat Tarik (Tensile Strength) dan Kuat Pukul (Impact Strength)

Hasil penelitian untuk melihat pengaruh pelapisan Silane Coupling Agent (SCA) terhadap kuat tarik komposit dapat dilihat melalui diagram pada Gambar 1. Kuat tarik yang ditampilkan merupakan perbandingan komposit tanpa pelapisan SCA dan dengan pelapisan SCA. Hasil pengujian kuat tarik komposit jika dibandingkan antara komposit yang dilapisi SCA dan yang tidak dilapisi memperlihatkan peningkatan sebesar 21\%. Komposit tanpa pelapisan SCA jika ditinjau berdasarkan persyaratan mekanis papan partikel SNI 03-21052006 memenuhi persyaratan papan partikel tipe 8, sedangkan komposit dengan pelapisan SCA $1 \%$ berat komposit memenuhi persyaratan papan partikel tipe 12. Proses pelapisan SCA pada komposit menunjukkan bahwa SCA dapat meningkatkan ikatan antara resin dan serat menjadi lebih baik. Hasil ini akan ditinjau morfologinya dengan melihat hasil pencitraan morfologi Scanning Electron Microscope (SEM) pada pembahasan selanjutnya.

Tabel 1. Persyaratan Mekanis Papan Partikel SNI 03-2105-2006

\begin{tabular}{ccc}
\hline Jenis Papan Partikel & Tipe & $\begin{array}{c}\text { Keteguhan tarik (Tensile Strength) } \\
\left(\mathbf{k g f} / \mathbf{c m}^{\mathbf{2}}\right)\end{array}$ \\
\hline Papan partikel biasa dan papan & 18 & 3,1 \\
partikel dekoratif & 13 & 2,0 \\
& 8 & 1,5 \\
\hline
\end{tabular}




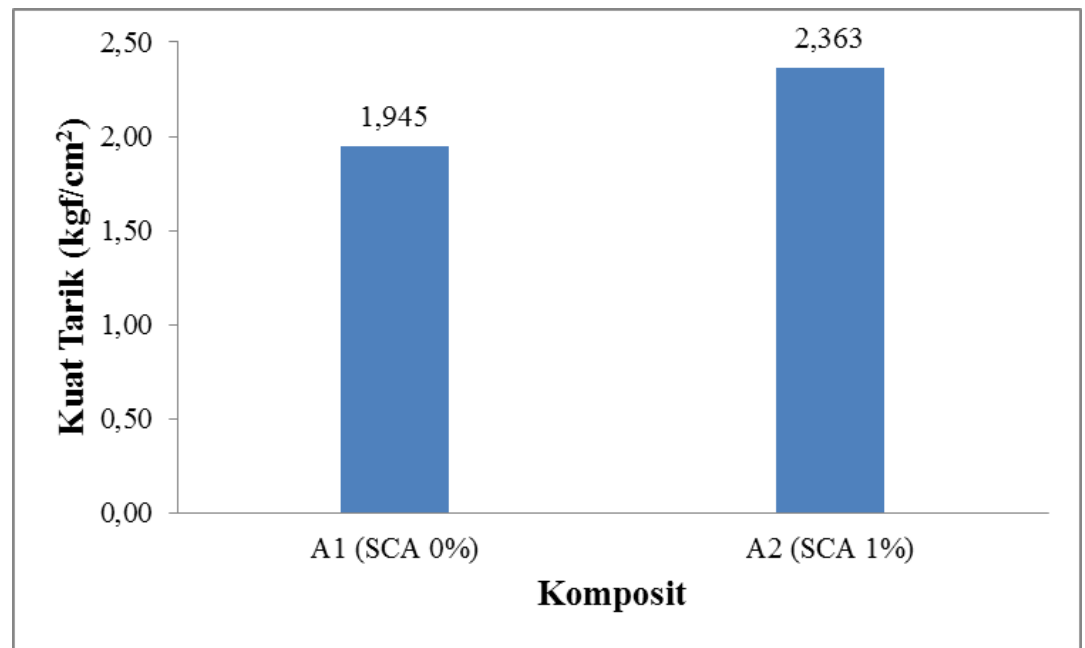

Gambar 1. Perbandingan Kuat Tarik Komposit tanpa pelapisan dan dengan pelapisan SCA $1 \%$

Hasil pengujian untuk melihat pengaruh pelapisan Silane Coupling Agent (SCA) terhadap kuat pukul komposit dapat dilihat melalui diagram pada Gambar 2. Nilai kuat pukul yang ditampilkan merupakan perbandingan komposit tanpa pelapisan SCA dan dengan pelapisan SCA. Hasil pengujian kuat pukul komposit jika dibandingkan antara komposit yang dilapisi SCA dan yang tidak dilapisi memperlihatkan peningkatan sebesar 13\%. Ikatan antar resin dan serat yang diperbaiki dengan pelapisan SCA mampu mengurangi transfer stress permukaan komposit sehingga dapat meninggkatkan ketahan komposit terhadap daya pukul yang disebabkan oleh beban.

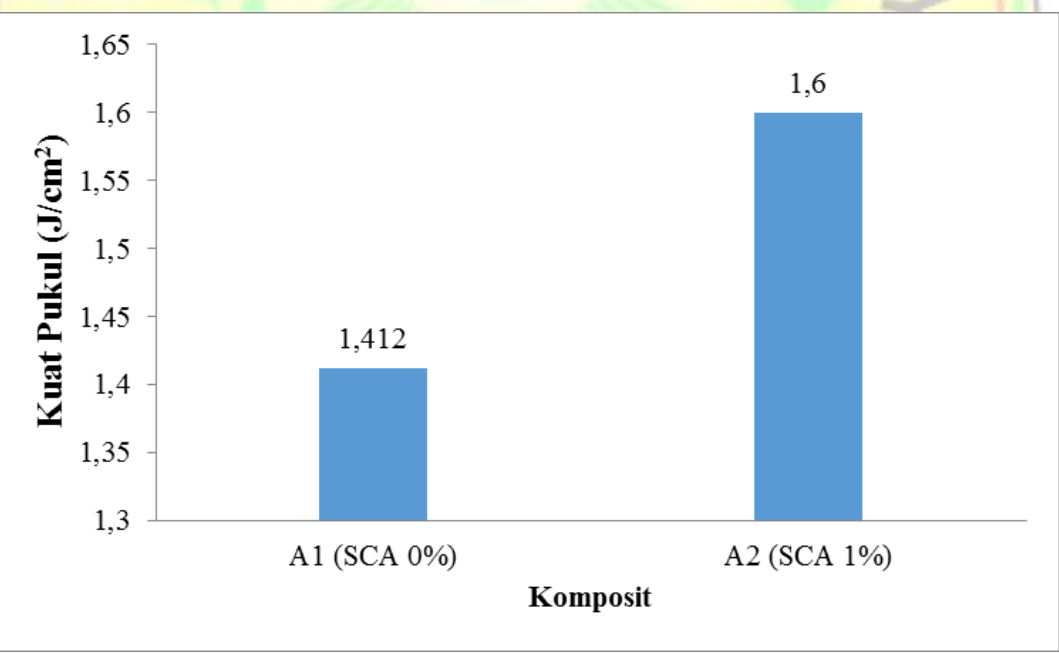

Gambar 2. Perbandingan Kuat Pukul Komposit tanpa pelapisan dan dengan pelapisan SCA 1\%

B. Pencitraan morfologi Scanning Electron Microscope (SEM)

Hasil pencitraan Scanning Electron Microscope (SEM) permukaan penampang patahan komposit setelah pengujian tarik dapat dilihat pada Gambar 3. Gambar 3.(a) memperlihatkan hasil pencitraan permukaan penampang patahan komposit tanpa pelapisan SCA dengan perbesaran 45, sedangkan Gambar 3.(b) memperlihatkan hasil pencitraan permukaan penampang patahan komposit dengan pelapisan SCA 1\% dengan 
perbesaran 45, dari kedua gambar tersebut dapat terlihat untuk komposit tanpa pelapisan ikatan antara resin dan serat masih lemah, hal ini diperlihatkan dengan banyak gumpalan pada permukaan komposit. Sedangkan pada permukaan penampang patahan komposit dengan pelapisan SCA 1\% ikatan antar resin dan serat diperbaiki, gumpalan berkurang, sejalan dengan peningkatan ikatan antar resin dan serat.

Gambar 3(c) dan 3(d) merupakan pencitraan penampang patahan komposit tanpa pelapisan dan dengan pelapisan SCA 1\% dengan perbesaran 5000, pada gambar ini ikatan antar resin dan serat dapat dilihat lebih dalam, penampang patahan komposit tanpa pelapisan memiliki lebih banyak butir (grain), seperti yang diketahui butir dapat memicu retakan memanjang yang menjadi penyebab penampang patahan. Pencitraan penampang patahan komposit dengan pelapisan SCA 1\% memperlihatkan batas butir berkurang sehingga dapat mengurangi pemicu penampang patahan dan secara efektif SCA dapat mengisi void pada permukaan dan meningkatkan kuat tarik antar resin dan serat, sehingga secara efektif juga meningkatkan kuat tarik komposit.

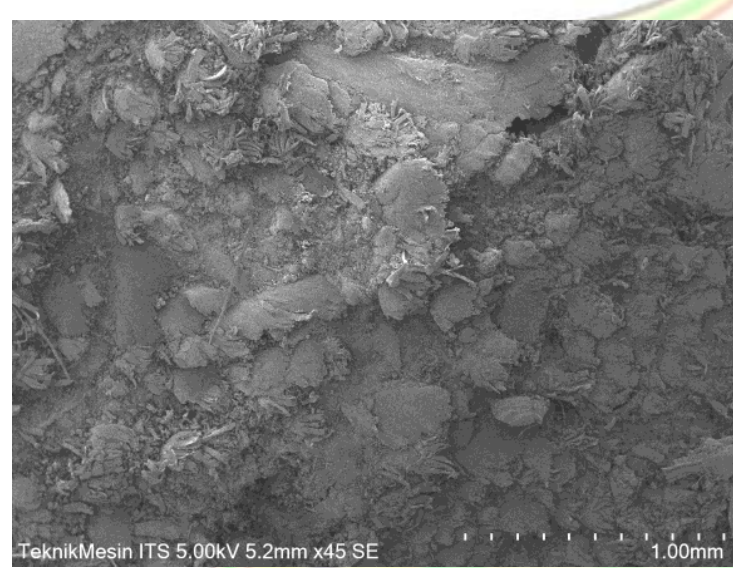

(a)

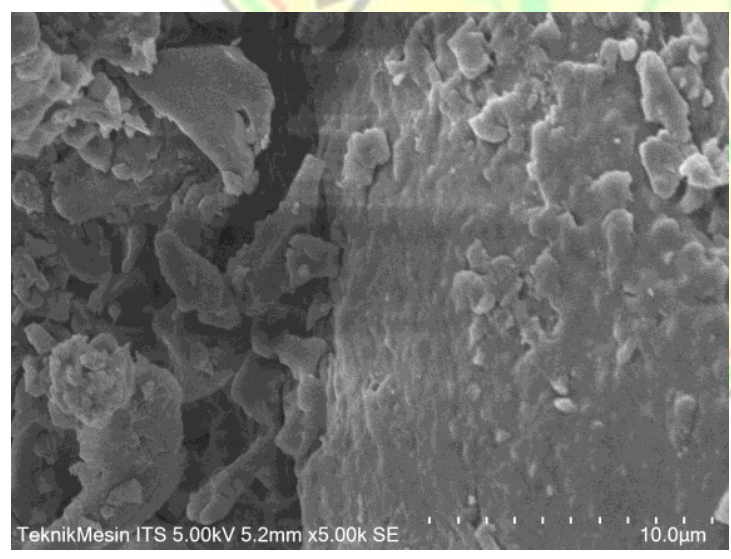

(c)

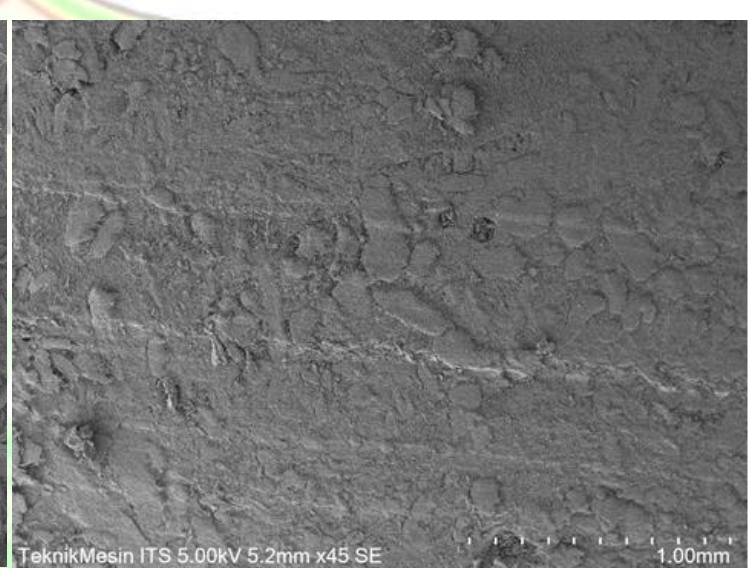

(b)

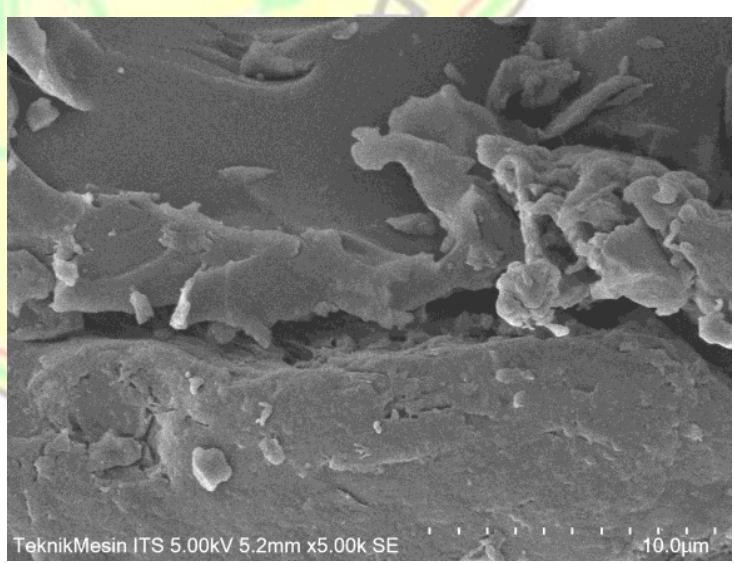

(d)

Gambar 3. Hasil Pencitraan Scanning Electron Microscope (SEM) (a)Penampang Komposit Tanpa Pelapisan SCA Perbesaran 45 (b)Penampang Komposit Dengan Pelapisan SCA Perbesaran 45 (c)Penampang Komposit Tanpa Pelapisan SCA Perbesaran 5000 (d)Penampang Komposit Dengan Pelapisan SCA Perbesaran 5000 


\section{Daya Serap Air}

Hasil pengukuran daya serap air pada komposit dapat dilihat pada Gambar 4. Nilai daya serap air komposit dengan pelapisan SCA $1 \%$ menurun sebesar 34\%. Proses pelapisan SCA pada komposit memungkinkan untuk silane masuk pada celah komposit dan berikatan dengan serat dan resin sehingga mempersempit celah untuk masukkan air pada komposit.

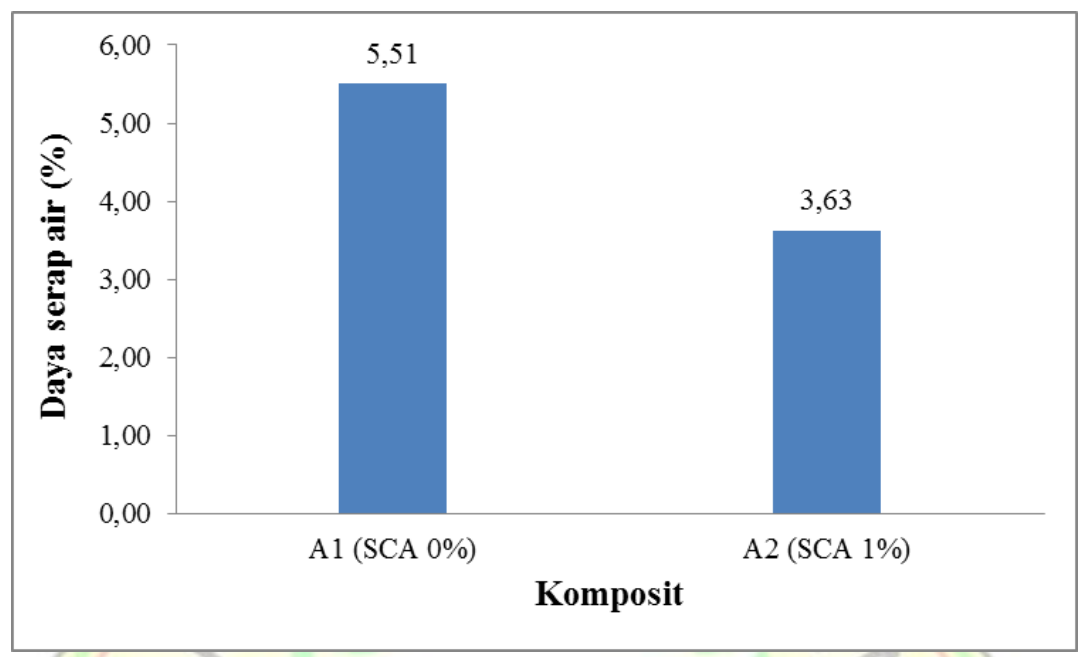

Gambar 4. Perbandingan Daya Serap AIr Komposit tanpa pelapisan dan dengan pelapisan SCA 1\%

\section{Kesimpulan}

Penelitian ini telah berhasil membuat kompsoit dari libah tandan kosong kelapa sawit dengan serat kenaf menggunakan resin epoksi. Berdasarkan hasil penelitian pelapisan Silane Coupling Agent (SCA) telah berhasil meningkatkan ikatan antara serat kenaf, tandan kosong sawit dan epoksi sehingga secara efektif dan sejalan dengan peningkatan kuat tarik, kuat pukul dan daya serap air.

\section{Ucapan Terimakasih}

Tulisan ini merupakan bagian dari hasil penelitian yang telah didanai oleh Program Penelitian Dosen Pemula Tahun 2019. Oleh sebab itu penulis mengucapkan terima kasih kepada Kementerian Riset, Teknologi dan Pendidikan Tinggi sebagai penyandang dana, Lembaga Penelitian Universitas Muhammadiyah Riau dan Program Studi Fisika Fakultas MIPA dan Kesehatan yang telah memberikan kesempatan untuk melaksanakan penelitian ini, serta berbagai pihak yang telah membantu dalam pelaksanaan dan penyelesaian penelitian ini.

\section{Daftar Referensi}

Fiore, V., Di Bella, G., Valenza, A. 2015. The effect of alkaline treatment on mechanical properties of kenaf fibers and their epoxy composites. Composites Part B: Engineering, 68, 14-21.

Datta, J., dan Kopczyńska, P. 2015. Effect of kenaf fibre modification on morphology and mechanical properties of thermoplastic polyurethane materials. Industrial Crops and Products, 74, 566-576. 
Kementrian Perdagangan Republik Indonesia. 2013. Statistik Perdagangan. Jakarta: Kementrian Perdagangan Republik Indonesia.

Liu, Yinan, Limin Guo, Weihong Wang, Yanan Sun, and Haigang Wang. "Modifying wood veneer with silane coupling agent for decorating wood fiber/high-density polyethylene composite." Construction and Building Materials 224 (2019): 691-699.

ASTM. D 638-14. Standard Test Methods For Tensile Properties of Plastics. Philadelphia, PA: American Society for Testing and Materials.

ASTM. D 256-04. Standard Test Methods For Determining The Izod Pendulum Impact Resistance of Plastics. Philadelphia, PA: American Society for Testing and Materials.

ASTM D 570. Standard Test Method for Water Absorption Materials, Philadelphia, PA: American Society for Testing and Materials.

Badan Standarisasi Nasional. 2006. SNI-03-2105-2006 (Revisi SNI-03-2105-1996. Mutu Papan Partikel.BSN. Jakarta.

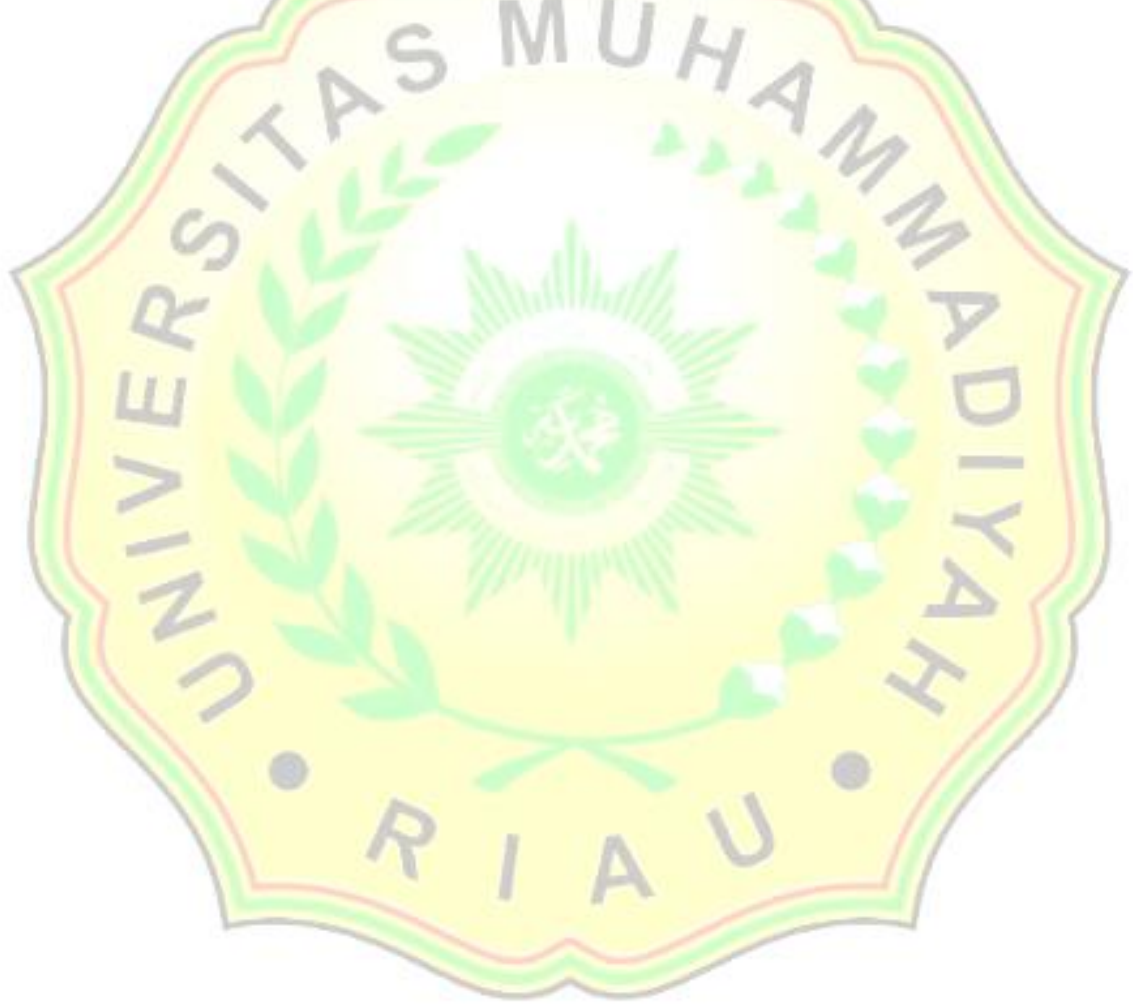

